\title{
Toxicity and Fate of Heavy Metals with Particular Reference to Developing Foetus
}

\author{
Anju Agrawal
}

Department of Zoology, SNSenBVPG College, CSJM University, Kanpur, India

\begin{abstract}
Heavy metals especially lead, mercury, cadmium, arsenic and chromium are well known for causing birth defects. Although, the mother may be unaffected and unaware of the contamination, infants exposed to such agents in-utero may have a number of side effects as these substances readily move across the placental barrier. Heavy metals are dangerous because they have the tendency to bioaccumulate in biological organisms over a period of time. The foetus and newborns are much more sensitive to the effects at low levels of metal exposure and this is mainly due to body weight being less and higher rate of food consumption rate, higher gastrointestinal absorption rate, less effective renal excretion, and a less effective blood-brain barrier. On the other hand, lead is tightly bound to red blood cells, thereby enhancing the transfer from maternal circulation through the placenta to the foetus. Placental transfer begins as early as the twelfth week of gestation. Arsenic is found in drinking water and is a potent toxicant but scanty research has been done on its effect on maternal health. Chromium $\left(\mathrm{Cr}^{6+}\right)$ accumulates in placenta and impairs foetal development in the placenta. Therefore, the fertile population should prevent themselves from exposure to chemicals, drugs and other environmental agents.
\end{abstract}

Keywords Heavy Metals, Foetus, Mercury, Lead, Cadmium, Arsenic, Chromium

\section{Introduction}

A number of researches over the last century has clearly established the relationship between the developing infant and the environment. There may be positive or negative effect of environment on the infant both in pregnancy and post birth. There is a long list of possible teratogenic and mutagenic agents. Birth defects are of number of types i.e. from infant mortality, to neurobehavioral dysfunction (including mental retardation) and numerous physical dysmorphologies (including retarded growth). Actual percentage of birth defects by environment (including drugs) is not known, but 2-3\% of birth defects have a known environmental or drug [1] origin. Therefore, the fertile population should prevent themselves from exposure to chemicals, drugs and other environmental agents. Alcohol, pharmaceutical and non pharmaceutical drugs, cigarette smoking, bacterial and viral pathogens, heavy metals and radiation are some of the causes of birth defects due to environment.

Heavy metals especially lead, mercury, cadmium, arsenic and chromium are known to cause birth defects. Although the mother may be unaffected and unaware of the contamination, infants exposed to such agents in-utero may have serious health side effects as these substances readily

* Corresponding author:

anjuagrawa12@gmail.com (Anju Agrawal)

Published online at http://journal.sapub.org/als

Copyright (C) 2012 Scientific \& Academic Publishing. All Rights Reserved move across the placental barrier. Mercury contamination may occur through the consumption of large fish which has a greater amount of mercury in their systems. There are a number of neurological symptoms, which are found to be associated with birth defects viz. 'blindness, deafness, lack of coordination, and intellectual impairment'.

Lead is one of the major environmental cause of birth defects which causes mental retardation and psychomotor dysfunction. It may be absorbed in the gastrointestinal tract or lung tissue and the damage occurs in the red blood cells, kidney tissue and gastrointestinal tract. Iron utilization by the red blood cells is thereby reduced, which results in anaemia which may later present sign of lead poisoning. Lead is mostly stored in the bone tissue, competing with calcium for remodelling and finally it is excreted out by the kidneys. The absorption rate of lead increases with the deficiencies in zinc, calcium and/or iron. Common sources of lead are paint, soil, water and newsprint.

The most important thing for the female and the developing foetus is maternal nutrition. The mother and foetus should be well nourished but a number of environmental contaminants lead to birth defects. The adverse reproductive outcomes on the child include caffeine, mercury contaminated seafood and foods containing bacteria. High intake users have higher rates of foetal mortality. The teratogenic effects are potentiated with exposure in the third to twelfth week of pregnancy[2]. Heavy metals can enter water supply by industrial and consumer waste, or even from acidic rain thus breaking down soils and releasing into streams, lakes, 
rivers, and ultimately finds way into groundwater. Heavy metals are natural components of earth crust and they can enter the water and food cycles through a variety of chemical and geochemical processes[3]. The increase in population and advancement in technology has lead to environmental concerns due to indiscriminate dumping of refuse and discharge of effluents, petroleum, waste water and crude oil spills out of which the most common are the heavy metals in the environment[4]. Activities of human beings in recent years have increased the quality and distribution of heavy metals in the atmosphere, land and water bodies. Water, sediments and biota are generally metal reservoirs in aquatic environments[5]. The concentration of heavy metals may vary considerably depending on annual and seasonal fluctuations. The extent of accumulation in biota is dependent on the chemical effects of the metal, its tendency to bind to particular materials and on the lipid content and composition of the biological tissue. In recent years, a number of activities have increased the quantity and distribution of heavy metals in the atmosphere, land and water bodies. The widespread and diffused contamination has raised concern about there hazards on plants, animals and humans.

\section{Mechanism of Heavy Metal Toxicity}

Toxicity occurs when the body accumulates an excessive amount of heavy metal, such as mercury, lead, arsenic, cadmium, aluminium or nickel. This places the individual at risk for serious illness. Some elements are disturbed such as selenium, which is an effective antioxidant, iron, which is required by blood cells, and copper, which is an integral part of many enzymes. These heavy metals can accumulate in the tissues (as they have storage sites in the body) over a period of time and cause serious health problems.

Toxicity from mercury, in common with the other heavy metals, arises from environmental contamination and also from some unexpected sources. With mercury, it is the nature of the environmental sources that are particularly worrying in the context of nutrition. Mercury enters the environment mainly through industrial discharges such as from chloroalkali plants, electrical apparatus production plants, agricultural industry which use a large number of fungicide for seed dressings. Sewage effluent from these industries sometimes contain mercury upto ten times the concentration of natural water. When the mercury is adsorbed on sediments in the water bodies, the sulphate reducing bacteria in sediments generates methyl mercury $\left(\mathrm{CH}_{3} \mathrm{Hg}\right)$ and dimethyl mercury $(\mathrm{CH} 3)_{2} \mathrm{Hg}$ which volatilises out and is released in the water where it is absorbed by the fish from the water. The $\mathrm{CH}_{3} \mathrm{Hg}^{+}$ion forms $\mathrm{CH}_{3} \mathrm{HgCl}$ in the saline biological fluids, and this neutral complex passes through biological membranes and is distributed throughout the tissues of the fish. In the tissues the chloride is displaced by peptide sulphydryl groups. Since mercury has an affinity for sulphur ligands, the methyl mercury is eliminated slowly and this leads to bioaccumulation which in turn causes toxicity when small fish is being eaten by bigger fish. Biomethylation of mercury occurs in all sediments and fish. But the levels are greatly elevated in bodies of water for which sediments are contaminated by mercury from waste effluents. The worst case of environmental mercury poisoning occurred in the 1950s in Minimata, Japan, where fish accumulated methyl mercury to levels approaching $100 \mathrm{ppm}$. Thousands of people were poisoned and hundreds died from the poisoned fish. Since methyl mercury is able to cross the blood-brain barrier, it affects the brain. Similarly methyl mercury can pass from mother to foetus, thereby causing mental retardation and motor disturbance in a number of infants.

\subsection{Biotransformation and Bioaccumulation of Heavy Metals}

Microbes have evolved diverse strategies to overcome the toxic effects of metals and metalloids, thereby it reduces their bio-availability or toxicity through biomethylation and transformation. The elevated concentrations of waterborne heavy metals have been recognized as an environmental problem in aquatic ecosystems throughout the world. Some of these heavy metals reach ground water and others accumulate in seafood or in plants and represent a major toxic source for humans. Some of them cause deformation of birds and sea animals in addition to some diseases in humans.

The rhizosphere is a site of increased microbial activity that may enhance accumulation, transformation, degradation, and biomethylation of selinium and other trace elements. Microbes in the rhizosphere are known to facilitate the removal of toxic heavy metals or metalloids originating from wastewaters through biosorption, sulfide-precipitation, and biotransformation. Plants provide a suitable environment, fixed carbon and other nutrients to the microbes in the rhizosphere. This occurs through root exudation and plant decomposition[5].

\subsubsection{Heavy Metal Toxicity from Drinking Contaminated Water and Fish}

Humans are exposed to drinking water containing heavy metals at levels exceeding the safe upper limit. Lead plumbing causes lead contamination in older homes and soldered joints in copper pipes. Other heavy metals include copper and arsenic which are found in tap water. Copper serves as a co-factor for many enzymes and is required in the diet in small amounts for normal health. Higher doses of copper are dangerous to health. A single dose of $15 \mathrm{mg}$ copper can cause nausea, vomiting, diarrhoea and abdominal pain. Contamination of copper may cause damage to liver and kidney. The corrosion of copper pipes leads to accumulation of copper in tap water which can accumulate overnight. In this case flushing the tap before using the water is highly recommended. Arsenic has been found in tap water in levels substantially exceeding the EPA safe limit in several areas of the country. Arsenic levels below the current limit of 10 parts per billion causes risk of cancer, the EPA has set new standards of $10 \mathrm{ppb}$ to be effective from 2006 . 
Mercury which causes environmental contamination eventually enter our water system through soil, rivers, streams and lakes. The form of mercury in our drinking water is in the inorganic form, which can easily be converted to the organic form, methylmercury, which on action by bacteria is present in soil and water environments. In this form it eventually enters our food chain. The maximum level of mercury in drinking water permitted by the EPA is 2 parts per billion. Although the level of mercury in tap water are generally within this limit, there have been reports of mercury exceeding the EPA safe limit in several areas of the country, most notably from well sources. All fish are not contaminated by mercury. Fish is high in omega-3 polyunsaturated fatty acids which is known to be beneficial to cardiovascular health. Therefore all fish should not be avoided. There are many types of fish available and farm raised fish is one option. Only trace amounts of mercury, 40-100 times below the safe limit were found in common commercially produced fish.

\subsubsection{Mercury Toxicity from Dental Fillings and Vaccination}

Dental amalgams, or "silver fillings" contain about 50\% mercury along with silver, tin, copper and zinc. Mercury tends to leach from the amalgam with release of mercury vapour so over time there is a real risk of a toxic load to the body posing a real health risk. The simple fact alone is that mercury is highly toxic to the human body and that mercury release from amalgam is harmful. Despite the dangers that exist in mercury, it is still used in dental fillings. Mercury toxicity can be overcome from vaccinations containing thermosal as a preservative.

\section{Metabolism of Mercury}

Mercury is more volatile than other sulfhydryl-reactive metals and therefore it is more highly absorbed in elemental $(\mathrm{Hg})$ form. Mercury enters water as natural process of gasping from the earth's crust and as a result of industrial pollution. Mercury is methylated by algae and bacteria in water and moves up the food chain to highest concentrations in large predatory fish such as swordfish, shark, salmon and tuna. The two major, highly absorbed sub-species of mercury are elemental $\mathrm{Hg}$ and methyl mercury $(\mathrm{MeHg})$. Although $\mathrm{Hg}$ is poorly absorbed if ingested, its vapour are efficiently absorbed through the lungs and quickly passes into the brain through the blood brain barrier. Due to its lipophilic nature, it has a high affinity for myelin and lipid membranes. Once inside the cell it is oxidised by catalase to highly reactive $\mathrm{Hg}^{2+}$. Methyl mercury (MeHg), derived from fish, and dimethyl mercury are readily absorbed in the gastrointestinal tract. $\mathrm{MeHg}$ can be demethylated and oxidized to $\mathrm{Hg}^{2+}$. Once assimilated in the cell, $\mathrm{Hg}^{2+}$ and $\mathrm{MeHg}^{+}$form covalent with glutathione and cysteine residues of proteins. A significant proportion of the assimilated $\mathrm{Hg}$ is retained which continu- ally accumulates in the kidneys, neurological tissue and the liver as it has low excretion rates.

It has been demonstrated that $\mathrm{Hg}$ not only directly removes GSH from the cell, but also inhibits the activities of two key enzymes involved in GSH metabolism: GSH synthetase and GSH reductase. Mercury also inhibits the activities of free radical quenching enzymes catalase, superoxide dismutase and perhaps GSH peroxidase. In addition to promoting lipid peroxidation, depleting GSH and inhibiting antioxidative processes, the sulfhydryl reactive metals disrupts the structure and function of numerous proteins through direct binding to free sulfhydryl group. Intact sulfhydryl groups are critical for biological activities of virtually all proteins including $\mathrm{Na} / \mathrm{K}$ ATPase. Metal induced inhibition of $\mathrm{Na} / \mathrm{K}$ ATPase can result in astrocytes swelling and destruction[6]. Mercury inhibits the polymerization of existing microtubles. Animal studies show that lesions in brains of animals closely resemble those found in patients with Alzheimer's disease[7].

\subsection{Effect of Mercury Exposure on Fertility and Foetal Development}

Recent studies have shown that reproductive effects including infertility and developmental effects in the foetus and infants are at much lower levels and do not have any significant effects on adults. When compared to adults, the foetus and newborns are much more sensitive to the effects of low levels of mercury exposure due to low body weight with higher food consumption rate per kilogram of body weight, higher gastrointestinal absorption rate, less effective renal excretion, and a less effective blood-brain barrier[8].

The most common source of maternal exposure to mercury vapour, is amalgam fillings, while the most common sources of methyl mercury in people are amalgam[9] and fish. These two are known to rapidly penetrate the placenta and than to the foetus[10-21]. The foetal mercury content after maternal inhalation, was found to be over 20 times that for maternal exposure which has been found to be an equivalent dose of inorganic mercury[22], and levels of mercury in the brain, heart, and major organs have been found to be higher after equal exposure levels to mercury vapour than for the other mercury forms $[23,24]$. Some developmental and behavioural effects from mercury vapour have been found at levels considerably below that required for similar effects by methyl mercury[25-27]. The studies reviewed found that mercury vapour and organic mercury have independent and synergistic toxic and developmental effects along with those of other toxic metals such as nickel, palladium, gold, and cadmium, and that additional conversions occur in the body between the various forms of mercury[28,29]. Extensive immune system tests for populations of patients with chronic autoimmune diseases such as Chronic Fatigue Syndrome or chronic neurological conditions have shown that a much higher percentage of the patients have autoimmune reactions to inorganic mercury than to organic mercury, and that immune reactivities and 
symptoms improve in the majority of cases when amalgam fillings are replaced.

Animal studies using rats, sheep, and monkeys as well as human studies have shown that mercury from amalgam in the blood of pregnant women crosses the placenta and appears in amniotic fluid and foetal blood, liver, and pituitary gland within the time period of 2 days of placement. A significant correlation has been found between number of amalgam fillings of the mother and the level of mercury in the foetus, infants, and young children, and also with the level in mother's milk. Breast milk has been found to increase the bioavailability of inorganic mercury, which was found to be excreted in milk from blood at a higher level than organic mercury[17,30]. The main mechanism of transfer was found to be binding to albumin. For non-occupationally exposed populations and populations without high fish consumption, these studies found dental amalgams appear to be the main source of mercury in breast milk and the foetus, but significant levels of methyl mercury are also often found in breast milk[30]. U.S. ATSDR staff[31] indicated that under normal circumstances mercury in mother's milk should be less than $1.7 \mathrm{ug} / \mathrm{L}$, and $3.5 \mathrm{ug} / \mathrm{L}$. This appears to be an adequate screening level for health risk.

Mercury is often stored in breast milk and the foetus is at a much higher level than that in the mother[30]. Milk from mothers with seven or more fillings was found to have levels of mercury approximately ten times that of amalgam free mothers. The milk sampled ranged from 0.2 to $57 \mathrm{ug} / \mathrm{L}$. In a population of German women, the concentration of mercury in early breast milk ranged from 0.2 to $20.3 \mathrm{ug} / \mathrm{L}$. After 2 months lactation the level had declined and was 0.1 to 11.7 $\mathrm{ug} / \mathrm{L}[32]$.

Meconium (first stool) level appears to be the most reliable indicator of foetal mercury exposure and often has significant levels when there are low levels in mother's blood and cord blood. The level of maternal blood or hair mercury is significantly correlated with mercury level in meconium and in nursing infants, so maternal tests can be easily used as a screen for developmental dangers[33]. But foetal levels can be significant even when there are low levels in maternal blood.

The highest levels of mercury are usually found in the pituitary gland of the foetus which affects development of the endocrine, immune, and reproductive systems. Mercury has been well documented to be an endocrine system disrupting substance in and humans, preferentially accumulating in and disrupting the function of the pituitary gland[34], hypothalamus, and thyroid gland[35]. It also disrupts or blocks enzyme production processes[25,36-39], glucose transfer, and many hormonal functions[40-44] at very low levels of exposure. The pituitary gland controls many of the body's endocrine system functions and secretes hormones that control most bodily processes, including the immune system and reproductive systems[45]. The hypothalamus regulates body temperature and many metabolic processes.

\subsubsection{Effect of Mercury on Fertility}

In pregnant women mercury passes through the placental membrane and causes permanent damage to the brain of developing baby. A special relationship exists between the mother and the foetus regarding mercury distribution. Much higher levels of methylmercury have been reported in cord blood as compared to maternal blood. Experiments in animals have conferred that there is a much higher accumulation of mercury in the foetal brain tissue than in the maternal brain tissue. There is a disturbance in hormone and immune system due to mercury exposure and this reduces fertility. Persons dealing with dental problems have reduced fertility as they are most exposed to mercury. Female fertility cycle events are mostly related to posterior pituitary activity, so amalgam is another factor that can disturb fertility as well as functions that are unrelated to pregnancy. Function of estrogen, an important hormone of the female fertility is also influenced by amalgam. A guideline to endocrine balance is blood serum phosphorus. If the phosphorus is below 3.5 $\mathrm{mg} \%$, there is an endocrine disturbance, somewhat related to the degree of drop below 3.5. The sex hormones are the most effective hormones in balancing the phosphorus level. All males and females produce both estrogen and testosterone. The males produce more testosterone and the females more estrogen, but there is a balance between the two in both sexes. Small doses of both hormones are used in both sexes to balance the serum phosphorus.

The menstrual and reproductive cycles are controlled by a very complex feedback mechanism between the ovaries, hypothalamus, and the pituitary. In the case of follicle stimulating hormone (FSH), there is a negative feedback relationship with estradiol at all times. When estrogen levels are low, the release of leutinizing hormone (LH) is increased, and when estrogen levels are high, LH is decreased. This ebb and flow controls the hormonal function leading to ovulation and the mid-cycle surge of both LH and FSH and the reduction of LH and FSH at the luteal phase relates to a feedback relationship with progesterone. Progesterone is not secreted by the ovary until just before ovulation. This, in turn, provokes ovulation--progesterone secretion, which undergoes a tremendous increase. The high levels of progesterone and estrogen associated with the luteal phase combine to suppress FSH and LH during the corpus luteum phase. Mercury inhibits release of FSH from the pituitary by damaging membranes of cells in the anterior pituitary.

\subsubsection{Effect of Mercury on the Placenta}

The circulatory systems of the mother and foetus are separated by a very thin membrane in the placenta. The purpose of this membrane is to ensure that there is no actual mixing of maternal blood with the foetal blood. This placental membrane was formerly called the placental barrier. Its function was assumed to be one of protecting the foetus from possible damage from any of the potentially toxic drugs or substances that might be present in the mother's blood. The Thalidomide disaster in 1961 demonstrated that the 
passage of toxic substances from mother to foetus did occur and could result in tragic birth defects and deformities. Mercury reduces the blood's ability to carry oxygen and, although foetal blood flow might be normal, the reduced oxygen content of the blood would parallel the hypoxic condition. Mercury may affect the balance or status of most of the body's essential nutrients. No scientific study has ever worked out the relationship between chronic mercury exposure and placental weight/birth weight. From the time of fertilization until birth, the offspring is dependent upon maternal sources for all nutrition.

There are four major areas that are considered to be critical or determinants in the outcome of foetal development: (1) the mother's nutritional status, (2) the structural and functional quality of the placenta, (3) the genetic makeup of the offspring, and (4) the presence of physical, chemical, or mechanical insults to mother and child during pregnancy. Mercury can also affect the satisfactory outcome of foetal development in all four of these areas.

One of the contributory factor in cadmium and mercury foetotoxicity may be an effect on the transmembrane transport of nutrients, such as amino acids, across the placenta to the foetus. An inhibition of nutrient transport may cause foetal death, congenital malformations, or growth retardation. The toxic effects of cadmium and mercury may be found in the placenta where presence of these metals prevent the passage of required nutrients to the embryo/foetus. The placental membrane will stop many substances. However, it is made of fat molecules, and mercury vapour and methylmercury, being fat-soluble, will penetrate the membrane. The lack of knowledge concerning the mechanisms of mercury toxicity is that it relates to the human reproductive cycle on which much scientific data does not exist. The majority of scientific studies on mercury have dealt with methylmercury or inorganic mercury. Very little attention has been paid to the threat posed by low-level chronic exposures to toxic metals. A great deal of the available scientific data was derived from observation of acute exposures where a large single injection of the toxic metal being investigated was administered and the results examined. While there is no barrier preventing the transfer of mercury, there is a slight barrier to the transfer of lead, and the greatest barrier is to the transfer of cadmium. Mercury vapour enters the body and its cells far more readily than most other forms of mercury.

The mercury concentrations in the placenta and the infant's hair are directly related to the infant's body burden of mercury. Total mercury and methylmercury, cadmium, and iron were higher in cord blood than in maternal blood, whereas copper and zinc were lower. Significant positive correlations were observed between maternal and cord blood with regard to total mercury and methylmercury, lead, cadmium, and manganese content. Significant correlations were also observed between many pairs of metals, particularly in the umbilical cord and its blood. These results suggest a more serious and complicated influence of heavy metals on infants than on their mothers. The presence of selenium in the placenta can modify and greatly reduce the transplacental passage of mercury to the embryo/foetus.

\section{Lead Metabolism}

In adults $5-10 \%$ of orally ingested lead is absorbed from the gastrointestinal tract. In children absorption is higher and values are of up to $30-50 \%$. Lead is inhaled as dust and accumulated on the lung surfaces. It is variably absorbed depending upon the particle size and the lead compounds involved. As much as $50 \%$ of the lead contained in automobile exhaust fumes reaches the blood stream. Absorbed lead is transported on the surface of the red cell and less than $5 \%$ is bound to plasma proteins. Lead is taken up by most tissues but, after equilibration is complete, more than $95 \%$ is deposited in skeletal bone as a lead phosphate complex. Lead is poorly excreted from the body and continued exposure causes tissue accumulation. The most important route of excretion is in urine, but normally this is less than $0.5 \mu \mathrm{mol} / 1$. On a group basis the increased excretion of lead in urine of exposed workers is a useful index, but individual variations are large.

The promotion of a lead diuresis by administration of chelating agents (penicillamine, EDTA) is a standard therapeutic measure in severe cases of symptomatic lead poisoning, then sequential measurements of urinary lead output are useful. Lead ions form complexes with ligands such as $-\mathrm{SH}$, and $-\mathrm{COOH}$ and the imidazole groups of proteins. This means that $\mathrm{Pb}^{2+}$ affects numerous enzyme pathways. Resulting into lessening energy metabolism. Protein and nucleic acid synthesis causes a reduction in cell division and effects on growth. Practical use is made of the inhibitory effects of lead on various stages of haem biosynthesis. A decrease in the activity of red cell $\alpha$-aminolaevulinic acid dehydratase (ALA-D) is seen even at low levels of lead exposure. Inhibition of ferrochelatase is detected by a build-up on the red cell of protoporphyin, and increase in plasma and tissue iron. Red cell protoporphyrin is in the form of a highly fluorescent Zn-protoporphyrin (ZPP) which can be measured readily with a filter fluorimeter. Inhibition of ALA-D is almost complete when blood lead concentrations reach $1.5-2.0 \mu \mathrm{mol} / 1$ at which point there is a detectable increase in red cell ZPP.

The continued inhibition by lead of haem biosynthesis and a reduction in protein synthesis causes anaemia, but this is now recognised as a late effect of lead poisoning. Lead poisoning can also be recognised through basophilic stippling of the red cells.

\subsection{Lead Toxicity and Its Effect on Reproductive Health}

There are evidences that chronic, excessive exposure has been associated with increased rates of infertility, miscarriage and still births and poor infant outcomes. In adult males, chronic lead exposure can result in decreased sex drive, impotence and sterility. Abnormalities in sperm counts and mortality have also been found. There is no evidence that male lead exposure leads to negative effect on the foetus of 
subsequent pregnancy. The toxicity of lead on adult female reproduction is decreased fertility, the ability to sustain pregnancy and pregnancy outcomes. High levels of lead exposure is usually associated with acute exposure and can lead to still births or miscarriage. Lower blood lead levels result from chronic low level exposure or mobilization of bone lead during pregnancy. This is associated with low birth-weight and pre term delivery.

Research indicates that exposure to lead during pregnancy is only one source from which a foetus can be exposed to lead. Pregnancy and breast feeding can cause a state of physiological stress that increases bone turnover of lead. Lead stored in the bone as a result of childhood lead poisoning moves into the blood, increasing the mother's blood level and passes to the foetus. Pregnancy, related hormonal changes affect calcium metabolism and also cause lead to leave bone and enter the blood. Whenever maternal blood lead becomes elevated it is available to the foetus and this can negatively effect foetal development.

\subsubsection{Maternal Transfer of Lead to Foetus}

Lead is tightly bound to red blood cells, enhancing transfer from maternal circulation through the placenta to the foetus. Placental transfer begins as early as the twelfth week of gestation. As in adults, lead can be found in foetal blood, soft tissue and bone. The foetus is more sensitive to lead because the foetus blood brain barrier is more permeable, the central nervous system is more vulnerable, and the foetus has less bone tissue for sequestering lead. Foetal exposure to lead is usually determined by measuring lead from umbilical cord blood samples taken at birth.

\subsubsection{Effect of Lead on Pregnancy}

Lead being a neurotoxin can carry a lethal legacy. Young women who live in lead-contaminated housing or who have lead-poisoned themselves as youngsters can pass lead on to their unborn foetuses. There is a strong correlation between maternal and umbilical cord blood lead levels, indicating the transfer of lead from mother to foetus[46]. Lead accumulates and is stored in bone for decades and these bone lead stores may pose a threat to women of reproductive age long after their exposure to lead has ended. In some studies, the contributions from endogenous (bone) and exogenous (environmental) sources on maternal blood lead levels were about equal[47]. Others suggest that skeletal lead stores are the dominant contributor to blood lead during pregnancy and the postpartum period[48]. In addition to transfer of lead prenatally, lead levels in breast milk also increase with the lead level in maternal blood, posing an additional risk to the neonate[49]. High calcium intake $(>2000 \mathrm{mg} /$ day) may attenuate pregnancy-induced increases in maternal blood lead concentrations by decreasing maternal bone resorption or demineralization during pregnancy and the subsequent release of lead from the bone[50]. The mobilization of bone lead stores in pregnant and post-partum women is particularly troublesome in view of work in children indicating that deleterious effects on cognitive development occur with placental blood lead levels below $10 \mu \mathrm{g} / \mathrm{dl}[51]$.

\section{Cadmium Toxicity}

Cadmium occurs as a minor component in most zinc ores and therefore is a byproduct of zinc production. Although cadmium is toxic, one enzyme, a carbonic anhydrase with cadmium as reactive centre has been discovered[52-54]. The most dangerous form of occupational exposure to cadmium is inhalation of fine dust and fumes, or ingestion of highly soluble cadmium compounds. Inhalation of cadmium- containing fumes can result initially in metal fume fever but may progress to chemical pneumonitis, pulmonary edema, and death. Cadmium is also a potential environmental hazard. Human exposures to environmental cadmium are primarily the result of fossil fuel combustion, phosphate fertilizers, natural sources, iron and steel production, cement production and related activities, nonferrous metals production, and municipal solid waste incineration. As a consequence, cadmium accumulates in the rice crops growing along the riverbanks downstream of the mines. Some members of the local agricultural communities consuming the contaminated rice developed itai-itai disease and renal abnormalities, including proteinuria and glucosuria[55]. The victims of this poisoning were almost exclusively post-menopausal women with low iron and other mineral body stores. Cadmium is a major factor in the Itai Itai disease in Japan, most researchers have concluded that it was one of several factors. There has been research linking exposure to cadmium to lung and prostate cancer. However, there is still a substantial controversy about the carcinogenicity of cadmium in the scientific community. More recent studies suggest that arsenic rather than cadmium may lead to increased lung cancer mortality rates. Tobacco smoking is the most important single source of cadmium exposure in the general population. It has been estimated that about $10 \%$ of the cadmium content of a cigarette is inhaled through smoking. The absorption of cadmium from the lungs is much more effective than that from the gut, and as much as $50 \%$ of the cadmium inhaled via cigarette smoke may be absorbed[56]. On an average, smokers have 4-5 times higher blood cadmium concentrations and 2-3 times higher kidney cadmium concentrations than non-smokers. Despite the high cadmium content in cigarette smoke, there seems to be little exposure to cadmium from passive smoking. No significant effect on blood cadmium concentrations could be detected in children exposed to environmental tobacco smoke[57].

\subsection{Placenta Toxicity Due to Cadmium}

The placental transfer of cadmium and its possible foetal effects is less known than lead and mercury. The placenta plays a complex and active role in reducing transfer of cadmium from mother to foetus. Studies relating maternal and cord blood levels of cadmium have shown that there is a 
maternal foetal gradient and that the placenta serves as a partial barrier to transplacental transport of cadmium.

High placental accumulations of cadmium results in trophoblastic damage which leads to a local circulatory response to the injured tissues and a decrease in uroplacental blood flow. It is the decrease in nutrient and oxygen transport to the foetus that results from trophoblastic damage and blood flow alterations that ultimately induces foetal death [58]. Researches also showed that circulatory alterations were found in Cadmium exposed rats with $40 \mathrm{~m} \mu$ moles $\mathrm{Cd} / \mathrm{Kgv}$. This results in trophoblastic necrosis, hemorrhage and congestion of maternal vascular spaces. These changes were indicative of local circulatory alterations.

\section{Arsenic Toxicity}

Arsenic poisoning interferes with cellular longevity of an essential metabolic enzyme by allosteric inhibition of pyruvate dehydrogenase $(\mathrm{PDH})$ complex which catalyzes the oxidation of pyruvate to acetyl-CoA by $\mathrm{NAD}^{+}$. This enzyme inhibition due to cell disruption results in cellular apoptosis. Biochemically, arsenic prevents use of thiamine resulting in a clinical picture resembling thiamine deficiency. Poisoning by arsenic raises lactate levels which leads to lactic acidosis. Low levels of potassium in the blood results in life- threatening heart rhythm problem from arsenic trioxide. Stimulation of Arsenic in the cells stimulates the production of hydrogen peroxide $\left(\mathrm{H}_{2} \mathrm{O}_{2}\right)$. Hydrogen peroxide on reaction with certain metals such as iron or manganese produces a highly reactive hydroxyl radical. Inorganic Arsenic trioxide found in groundwater affects voltage-gated potassium channels, which disrupts cellular electrolytic function resulting in neurological disturbances, cardiovascular episodes such as prolonged QT interval, neutropenia, high blood pressure[59], central nervous system dysfunction, anemia, leukemia, and death.

Another organism affected is vascular endothelial dysfunction which results due to arsenic exposure as it inactivates endothelial nitric oxide synthase this leads to reduction in the generation and bioavailability of nitric oxide. The exposure of arsenic leads to high oxidative stress, which inturn affects the structure and function of cardiovascular system. Exposure of arsenic leads to atherosclerosis which results in increase in the platelet aggregation and thereby reducing fibrinolysis Arrhythmia may be caused by arsenic exposure, thereby increasing the QT interval and accelerating the cellular calcium overload. The chronic exposure to arsenic also enhances the expression of tumour necrosis factor- $\alpha$, interleukin- 1 , vascular cell adhesion molecule and vascular endothelial growth factor to induce cardiovascular pathogenesis.

The first five leading causes of non-accidental death in the United States is arsenic, which brings the total amount to $1,525,675$ related mortalities. EPA is trying to reduce drinking water exposure to zero[60]. Leading causes of mortality in the world are also related to arsenic. These are namely[61] heart disease (hypertension related cardiovascular), cancer, stroke (cerebrovascular diseases), chronic lower respiratory diseases[62], and diabetes. These diseases are all related to the alteration of voltage dependent potassium channels. Researchers studied 788 adults who had their urine tested for arsenic exposure in the 2003-2004 National Health and Nutrition Examination Survey. Participants with type 2 diabetes had a $26 \%$ higher level of total arsenic in their urine than those without the disease. Diabetes is also related to alteration of voltage dependent potassium channels due in part to the function of insulin and potassium in the cellular metabolism of glucose. Due to the regular appearance of arsenic in public drinking water supplies, it is likely that arsenic plays a part in about thirty percent of total mortality in the United States. Arsenic prevalence in the water has been related to the occurrence of hypertension, erectile dysfunction and related conditions.

Chronic exposure to inorganic arsenic may lead to hypertension, involuntary muscular dysfunction, diabetes, neuropathy, depression, obesity and any other condition related to the altered role of intercellular voltage-dependent potassium channels, including cutaneous hyperpigmentation [63].

\subsection{Arsenicosis: Chronic Arsenic Poisoning from Drinking Water}

Chronic arsenic poisoning results from drinking contaminated well water over a long period of time. This is due to arsenic contamination of aquifer water. The World Health Organization recommends a limit of $0.01 \mathrm{mg} / \mathrm{L}(10 \mathrm{ppb})$ of arsenic in drinking water. This recommendation was established on the limit of detection of available testing equipment at the time of publication of the WHO water quality guidelines. More recent findings show that consumption of water with levels as low as $0.00017 \mathrm{mg} / \mathrm{L}(0.17 \mathrm{ppb})$ over long period of time can lead to arsenicosis.

\subsubsection{Effect of Arsenic on Foetal Health}

Arsenic is found in drinking water and is a potent toxicant, but scanty research has been done on its effects on maternal health. The mode of action of arsenic includes enzyme inhibition and oxidative stress as well as immune, endocrine, and epigenetic effects. Blood pressure and anaemia also increase during pregnancy. Susceptibility to arsenic is dependent on the biomethylation, which occurs via one-carbon metabolism. Methylarsonic acid and dimethylarsinic acid are main metabolites in urine, and elevated methylarsonic acid is considered a general risk factor. Easy passage of arsenic through the placenta, and a few human studies indicate a moderately increased risk of impaired foetal growth and increased foetal and infant mortality. The foetus and infant are probably partly protected by the increased methylation of arsenic during pregnancy and lactation. Low arsenic excretion in breast milk also protects the foetus. Early-life exposure may induce changes that will become apparent much later during the life. 
It is known that arsenic readily passes through the placenta to the foetus but not to breast milk[64]. Previous epidemiologic studies have suggested that there exists an association between arsenic exposure during pregnancy and low birth weight[65]. Arsenic was found to affect the T-cell subpopulation (helper $\mathrm{T}$ cells) from women ex vivo and also maturation of normal immune effector cells[66]. The exact mechanism of action of arsenic is not known but may involve oxidative stress, interference with hormones, especially glucocorticoids and estrogen, perturbation of DNA methylation, increased telomerase activity, and modulation of signal transduction pathways, all of which are important for intrauterine programming and foetal development[67-71].

\subsubsection{Placenta Toxicity Due to Chromium}

Chromium is an important trace element of living being. Elevation slightly of $\mathrm{Cr}^{6+}$ causes environmental and health problems because of its high toxicity, mutagenecity and carcinogenicity. Almost every regulatory agency has listed $\mathrm{Cr}^{6+}$ as a priority toxic chemical for control, with the maximum allowable level in drinking water of 50-100 $\mu \mathrm{gl}-1$ [72]. The United States Environmental Protection Agency (US EPA) has identified $\mathrm{Cr}^{6+}$ as one of the 17 chemicals posing the greatest threat to humans.

Chromium is taken up through the membrane sulfate transport channels in cells of sulfate-utilizing organisms[73]. Under normal physiological conditions $\mathrm{Cr}^{6+}$ reacts spontaneously with the intracellular reductants namely ascorbate and glutathione which generates short lived intermediates $\mathrm{Cr}^{5+}$ and $\mathrm{Cr}^{4+}$, free radicals and the end product is $\mathrm{Cr}^{3+} \cdot \mathrm{Cr}^{5+}$ later on undergoes a one electron redox cycle to regenerate $\mathrm{Cr}^{6+}$ and than it transfers the electron oxygen, produces a reactive oxygen species (ROS) that easily combines with DNA-protein complexes $\mathrm{Cr}^{4+}$ which binds to cellular materials and changes their normal physiological functions[74]. This $\mathrm{Cr}^{6+}$ accumulates in placenta and impairs foetal development in placenta[75].

\section{Conclusions}

Heavy metals are especially toxic to growing foetus. Unfortunately, heavy metals are not filtered by the placenta from mother to child and are directly deposited in growing foetal tissues. One of the main problems with heavy metals is their ability to bio-accumulate. All women planning to have children need to detoxify before conception. In detoxification of heavy metals firstly, the source of toxicity must be identified and removed. Secondly, the organs of excretion including: liver, kidneys, and lungs must be "opened" for detoxification. There are a number of environmental agents capable of producing birth defects if exposure exists during foetal life. Most important effect in the foetus is the amount of the teratogenic agent, the duration of the ingestion, the stage of placental development, the lipid solubility and molecular weight of the substance and crucially, the stage of foetal life in which the substance was ingested. Teratogenic agents are most harmful during the 3rd to 12th weeks of foetal life when organ differentiation is occurring but nonetheless, at any stage of the pregnancy harmful effects may be exerted. Pre-conceptual health care and pregnancy care from conception is of prime importance. Diagnostic screening tools, such as checking for immunity to Rubella or checking ante-natally for bacterial vaginosis should be routinely practiced to avoid unnecessary exposure of agents capable of producing birth defects.

\section{ACKNOWLEDGEMENTS}

Thanks are due to CST, Lucknow for providing financial assisstence.

\section{REFERENCES}

[1] C.Porth, Pathophysiology Concepts of Altered Health States (7th ed.). Lippincott-Raven Publishers: Philadelphia, pp147, 2005.

[2] R..E.Jones, K.H. Lopez. Human reproductive Biology $\left(3^{\text {rd }}\right.$ edition) Academic Press: Burlington, USA, 2006.

[3] I.J.Tinsley. Chemical concepts in pollutants behavior J. Wiley and Sans Inc 1979.

[4] J. Wills. A survey of offshore oil field drilling wastes and disposal techniques to reduce the ecological impact of sea dumping. Stakhlin Environ. Watch 13, 25-29, 2000.

[5] L.J.Warren. Contamination of sediment by lead, zinc and cadmium: a review: Environ. Pollution Series B Chemistry Physics 2, 401-436, 1981.

[6] M.Aschner, N.B.Eberle, K.Miller, H.K.Kimelberg, Interactions of methylmercury with rat primary astrocyte cultures : inhibition of rubidium and glutamate uptake and induction of swelling. Brain Res. 530, 245-250, 1990.

[7] J.C.Pendegrass, B.E.Hayley, M.J.Vimy, S.A. Winfield, F.L.Lorscheider. Mercury vapour inhalation inhibits binding of GTP to tubulin in rat brain: similarly to a molecular lesion in Alzheimer diseased brain. Neurotoxicol.18, 315-324, 1997.

[8] K.Kostial, M.Blanusa, T. Malikovic, Age and sex influence the metablolism and toxicity of metals. In: Trace Elements in Man and Animals (Monograph), Inst Med Res Occup Health, University of Zagreb, Yugoslavia , pp11/1-11/5, 1991.

[9] J.Leistevuo, T.Leistevuo, H.Helenius, L.Pyy, M.Osterbald, P.Huovinen, Dental amalgam fillings and the amount of organic mercury in human saliva. Caries Res. 35, 163-166, 2001.

[10] L.J.Hahn, R.Kloiber, R.W.Leininger, M.J.Vimy, F.L., Lorscheider, Distribution of mercury released from amalgam fillings into monkey tissues. FASEB J. 4, 5536,1990.

[11] N.D.Boyd, H.Benediktsson, M.J. Vimy, D.E. Hooper, F.L. Lorscheider, Mercury from dental silver tooth fillings impairs sheep kidney function". Comp. Physiol. 30, R1010-R1014, 1991. 
[12] Y.K.Soong, R.Tseng, C. Liu, J. Lin, P.W. Formosa. Med. Assoc. 90, 59-65, 1991.

[13] G.Drasch, S.Aigner, G.Roider, F.Staiger, G.Lipowsky, Mercury in human colostrums and early breast milk. J.Trace Elem. Med. Biol. 12, 23-27, 1998.

[14] P.Grandjean, P.J. Jurgensen, P. Weihe, Milk as a Source of Methylmercury Exposure in Inf. Environ. Health Persp. 102, 74-77,1994.

[15] K.Warfvinge, J. Hua, B. Logdberg. Mercury distribution in cortical areas and fibre systems of the neonatal and maternal cerebrum after exposure to mercury vapour. Environ. Res. 67, 196-208, 1994.

[16] M.C.Newland, K.Warfvinge, M.Berlin. Behavioural consequences of in utero exposure to mercury vapour. Toxicol. Appl. Pharmacol. 139, 374-386, 1996.

[17] A.Oskarsson, A.Schultz, S.Skerfving, I.P.Hallen, B. Ohlin, B.J.Lagerkvist. Mercury in breast milk in relation to fish consumption and amalgam. Arch. Environ. Health 51, 234-241, 1996.

[18] M.J.Vimy, D.E.Hooper, W.W.King, F.L.Lorscheider. Mercury from maternal silver tooth fillings: a source of neonatal exposure". Biol. Trace Elem. Res.56, 143-152, 1997.

[19] C.Y.Yang, C.C. Chang, S.S.Tsai, H.Y.Chuang, C.K.Ho, T.N.Wu, Arsenic in drinking water and adverse pregnancy outcome in an arseniasis-endemic area in northeastern Taiwan. Environ. Res.91, 29-34, 2003.

[20] G.Drasch, I.Schupp, H.Hofl, R.Reinki, G.Roider, Mercury burden of human fetal and infant tissues. Europ.J.Ped. 153, $607-610,1994$.

[21] E.Lutz, B.Lind, P.Herin, I.Krakau, T.H.Bui, M.Vahter, Concentrations of mercury, cadmium, and lead in brain and kidney of second trimester foetuses and Infants. J. Trace Elem. Med. Biol. 10, 61-67,2005.

[22] M.C. Newland, K. Warfvinge, M. Berlin. Behavioural consequences of in utero exposure to mercury vapour. Toxicol. Appl. Pharmacol. 139, 374-386, 1996.

[23] J.P.Buchet, Influence of DMPS on the mobilization of mercury from tissues of rats pretreated with mercuric chloride, phenylmercury acetate, or mercury vapour. Toxicol. 54, 323-333,1989.

[24] L.Magos, T.W.Clarkson, A.R.Hudson, The effects of dose of elemental mercury and first pass circulation time on organ distribution of inorganic mercury in rats. Biochim. Biophys. Acta 991, 85-89, 1989

[25] W.Y.Boadi, J.Urbach, J.M.Brandes, S.Yannai, In vitro effect of mercury on enzyme activities and its accumulation in the first-trimester human placenta. Environ. Res. 57, 96-106, 1992a.

[26] A. Fredrikson, L.Dencker, T.Archer, B.R. Danielsson, Prenatal exposure to metallic mercury vapour and methylmercury produce interactive behavioural changes in adult rats. Neurotoxicol. Teratol. 18,129-134, 1996.

[27] R.Leonhardt, M. Pekel, B.Plat, H.L.Hass, D. Busselberg. Voltage activated calcium channel currents of rat DRG neurons are redused by mercuric chloride and methylmercury. Neurotoxiccol.,17,85-92,1996.
[28] L.Tibbling, K.A.Thomas, R.Lenkei, V.Stejskal. Immunolocial and brain MRI changes in patients with suspected metal intoxication. Internat. J. Occupat. Med. Toxicol. 4, 285-294, 1995.

[29] V.D.M.Stejskal, A.Danersund, A.Lindvall, R.Hudecek, V.Nordman, A.Yaqob, W.Mayer, W. Bieger, U.Lindh. Metal-specific memory lymphoctes: biomarkers of sensitivity in man. Neuroend.Lett. 20, 289-298, 1999.

[30] K.Schumann. The toxicological estimation of heavy metal content $(\mathrm{Hg}, \mathrm{Cd}, \mathrm{Pb})$ in food for infants and small children. $\mathrm{Z}$. Ernahrungswiss 29, 54-73, 1990.

[31] H.G.Abadin, B.F.Hibbs, H.R.Pohl, Breast-feeding exposure of infants to cadmium, lead, and mercury: a public health viewpoint. Toxicol. Ind. Health 13, 495-517,1997.

[32] H. Dexler, K.H. Schaller. The mercury concentration in breast milk resulting from amalgam fillings and dietary habits. Env. Res. 77, 124-129, 1998.

[33] E.Cernichiari, R. Brewer, G.J.Myers, D.O.Marsh, M.Berlin, T.W.Clarkson, Monitoring methylmercury during pregnancy: maternal hair predicts foetal brain exposure. Neurotoxicol. $16,705-710,1995$.

[34] J.A.Weiner, N. Nylander. The relationship between mercury concentration in human organs and predictor variables. Sci.Total Environ. 138, 101-115,1993.

[35] B.Lindqvist, Effects of removing amalgam fillings from patients with diseases affecting the immune system. Med. Sci. Res. 24, 355-356, 1996.

[36] W.Y.Boadi, J.Urbach, J.M.Branes, S.Yannai, In vitro exposure to mercury and cadmium alters term human placentaml membrane fluidity. Toxicol. Appl. Pharmacol. 116, 17-23, 1992.

[37] J.Urbach, W. Boadi, J.M. Brandes, H. Kerner, S. Yannai, Effect of inorganic mercury on in vitro placental nutrient transfer and oxygen consumption, Rep. Toxicol.6 , 69-75, 1992.

[38] S.Hussain, D.A.Rodgers, H.M.Duhart, S.F.Ali, Mercuric chloride-induced reactive oxygen species and its effect on antioxidant enzymes in different regions of rat brain. Environ. Sci. Health B 32 , 395-409, 1997.

[39] D.Markovich, K.M.James, Heavy metals (Hg,Cd) inhibit the activity of the liver and kidney sulfate transporter Sat-1. Toxicol. Appl.Pharmacol. 154, 181-187,1999.

[40] I.Gerhard, B.Moonga, A.Waldbrenner, B. Runnebaum, Heavy metals and fertility. J. Toxicol. Environ. Health 54 , 593-611,1998a.

[41] I.Gerhard, S.Waibel, V.Daniel, B.Runnebaum, Impact of heavy metals on hormonal and immunological factors in women with repeated miscarriages. Human Reproduction Update 4, 301-309, 1998b.

[42] I.Gerhard, Amalgam aus gynakologischer Sicht. Der Frauenarzt 36, 627-628, 1995.

[43] T.Colborn, F.S.V.Saal, A.M.Soto, Developmental effects of endocrine-disrupting chemicals in wildlife and humans". Environ. Health Persp. 101, 378-384, 1993.

[44] I.Gerhard, B.Runnebaum, Environmental pollutants and 
fertility disorders. Geburtshilfe Frauenheilkd 52 , 383-396, 1992.

[45] T.Colborn (Ed.), Chemically Induced Alterations in Functional Development, Princeton Scientific Press, 1992.

[46] C.Gardella, Lead exposure in pregnancy: a review of the literature and argument for routine prenatal screening. [Review]. Obst. Gynecol. Survey 56, 231-238, 2001.

[47] H.Y.Chuang, J.Schwartz, T.Gonzales-Cossio, M.C.Lugo, E.Palazuelos, A.Aro, et al. Interrelations of lead levels in bone, venous blood, and umbilical cord blood with exogenous lead exposure through maternal plasma lead in peripartum women. Environ. Health Persp. 109, 527-532, 2001.

[48] B.L.Gulson, J.G.Pounds, P.Mushak, B.J.Thomas, B. Gray, M.J.Korsch, Estimation of cumulative lead release (lead flux) from the maternal skeleton during pregnancy and lactation. J. Lab. Clinical Med. 134, 631-640, 1999.

[49] P.J.Li, Y.Z.Sheng, Q.Y.Wang, L.Y.Gu, Y.L.Wang, Transfer of lead via placenta and breast milk in human. Biomed. Environ. Sci. 13, 85-89, 2000.

[50] M.A.Johnson. High calcium intake blunts pregnancy-induced increases in maternal blood lead. [Review]. Nutritional Rev. $59,152-156,2001$.

[51] D.C.Bellinger, Effect modification in epidemiological studies of low-level neurotoxicant exposures and health outcomes. [Review]. Neurotoxicol. Teratol. 22, 133-140, 2000.

[52] L.Jarup, "Health effects of cadmium exposure - a review of the literature and a risk estimate". Scand. J. Work Environ. Health 24, 11, 1998.

[53] K.Nogawa, E.Kobayashi, Y.Okubo, Y.Suwazono. Environmental cadmium exposure, adverse effects, and preventative measures in Japan. Biometals 17, 581-587, 2004.

[54] J.Zhou, W.Wang, Q.F.Wei, T.M.Feng, L.J.Tan, B.F.Yang, Effects of arsenic trioxide on voltage-dependent potassium channels and on cell proliferation of human multiple myeloma cells. Chinese Med. J. 120, 1266-1269, 2007.

[55] C.R.Kjeldsberg, M.D.Ward, P.Harry, "Brief Communications - Leukemia in Arsenic Poisoning". Annals Int. Med. 77, 935-937, 1972.

[56] D.Das, A.Chatterjee, B.K.Mandal, G.Samanta, D. Chakraborti, B.Chanda, Arsenic concentration in drinking water, hair, nails, urine, skin-scale and liver tissue (biopsy) of the affected people. Analyst 120, 917-925, 1995.

[57] R.L.Kingston, S.Hall, L.Sioris, "Clinical observations and medical outcome in 149 cases of arsenate ant killer ingestion". J. Toxicol. Clin. Toxicol. 31, 581-591, 1993.

[58] A.A.Levin, J.R.Plautz, P.A. diSant'Agnese, R.K. Miller, Cadmium placental mechanisms of fetal toxicity.Placenta (Suppl. 3), 303-318, 1981.

[59] C.K.Chong, C.P.Tseng, Y.M.Hsueh, H.Y. Chiou, C.C.Tseng, C.J. Chen, Long-term arsenic exposure and ischemic heart disease in arseniasis-hyperendemic villages in Taiwan.Tseng. Toxicol. Lett. 137, 15-21, 2003.

[60] A .N.Navas-Acien, 2008. Arsenic exposure and prevalence of Type 2 diabeties in US adults. JAMA 300, 814-822, 2008
[61] V.P.Korovkina, S.K.England, Detection and implications of potassium channel alterations. Vascular Pharmacol. 38, 3-12, 2002.

[62] M.Vahter, Effect of Arsenic on Maternal and foetal health. Ann. Rev. Nut. 29, 381-399, 2010.

[63] G.Concha, G. Vogler, B.Nermell, M.Vahter, Low-level arsenic excretion in breast milk of native Andean women exposed to high levels of arsenic in the drinking water. Internat. Arch. Occupat. Environ. Health 71 , 42-46, 1998.

[64] L.Vega, P.D.O.Montes, R.Saavedra, O.P.Wegman, Helper T cell subpopulations from women are more susceptible to the toxic effect of sodium arsenite in vitro. Toxicol.199, 121-128, 2004.

[65] T.C.Zhang, M.T.Schmitt, J.L.Mumford, Effects of arsenic on telomerase and telomeres in relation to cell proliferation and apoptosis in human keratinocytes and leukemia cells in vitro. Carcinogen. 24,1811- 1817, 2003.

[66] M.P.Waalkes, J. Liu, H. Chen, Y. Xie, W.F. Achanzr, Y.S Zhou, M.L.Cheng, B .A. Diwan. Estrogen signalling in livers of male mice with hepatocellular carcinoma induced by exposure to arsenic in utero. J. Nat. Cancer Inst. 96, 466-474, 2004.

[67] S.Chattopadhyay, S.Ghosh, S. Chaki, J. Debnath, D. Gosh, Effect of sodium arsenite on plasma levels of gonadotrophins and ovarian steroidogenesis in mature albino rats: duration-dependent response. J. Toxicol. Sci. 24, 425-431,1999.

[68] S.K.Murphy, R.L.Jirtle, Imprinted genes as potential genetic and epigenetic toxicologic targets. Environ. Health Persp. 108, $5-11,2000$

[69] A.Hartwig, H.Blessing, T.Schwerdtle, I.Walter, Modulation of DNA repair processes by arsenic and selenium compounds. Toxicol. 193, 161-169, 2003.

[70] S.Bekaert, H.Derradji, S.Baatout, Telomere biology in mammalian germ cells and during development. Develop. Biol. 274, 15-30, 2004.

[71] J.E.Bodwell, L.A.Kingsley, J.W.Hamilton, Arsenic at very low concentrations alters glucocorticoid receptor (GR)- mediated gene activation but not GR-mediated gene repression: complex dose-response effects are closely correlated with levels of activated GR and require a functional GR DNA binding domain. Chem. Res. Toxicol. 17, 1064-1076, 2004.

[72] M.D.La Grega, P.L. Buckingham, J.C.Evans, Hazardous waste management, second ed. Mc.Graw Hill, New York, 2001.

[73] S.Silver, J.Schottel, A.Weiss, Bacterial resistance to toxic metals determined by extrachromosomal $\mathrm{R}$ factors. Int. Biodet. Biodegrad. 48, 263-281, 2001.

[74] C.Cervantes, J.Garcia camppos, S. Devars, F. Guttierrez-Corona, H. Loza-Tavera, J.C. Torres-Guzman, R. Moreno-Sanchez, Interactions of chromium with microorganisms and plants. FEMS Microbiol. Rev. 25, 335-347, 2001

[75] D.K.Saxena, R.C. Murthy, V.K.Jain, S.V. Chandra, Fetoplacental-maternal uptake of hexavalent chromium administered orally in rats and mice. Bull. Environ. Contamin.Toxicol. 45, 430-435,1990. 